\title{
1 Seasonal Changes in the Diet and Feeding Behaviour of a Top \\ 2 Predator Indicates a Flexible Response to Deteriorating \\ 3 Oceanographic Conditions
}

4

5 Xavier, J. C. ${ }^{1,2}$, Louzao, M. ${ }^{3,4}$, Thorpe, S. E. ${ }^{2}$, Ward, P. ${ }^{2}$, Hill, C. ${ }^{2}$, Roberts, D. ${ }^{2}$, Croxall, J.

6 P. $^{2}$ and Phillips, R. A. ${ }^{2}$

7

$8{ }^{1}$ Institute of Marine Research, Department of Life Sciences, University of Coimbra, 3001-401

9 Coimbra.

$11{ }^{2}$ British Antarctic Survey, Natural Environment Research Council, High Cross, Madingley

12 Road, Cambridge, CB3 0ET, UK.

$14{ }^{3}$ Centre d’Etudes Biologiques de Chizé, CNRS UPR 1934, 79369 Villiers en Bois, France 15

$16{ }^{4}$ Helmholtz Centre for Environmental Research-UFZ, Permoserstraße 15, 04318 Leipzig, 17 Germany

19 Address for correspondence:

20 José C. Xavier Institute of Marine Research, Department of Life Sciences, University of

21 Coimbra, 3001-401 Coimbra.

22 E-mail: JCCX@cantab.net Phone: +351936728419

23

24

25

26

27 
Shifts in the diet of top predators can be linked to changes in environmental conditions.

30 In this study, we tested relationships between environmental variation and seasonal changes in

31 diet of a top predator, the grey-headed albatross Thalassarche chrysostoma, breeding at Bird

32 Island, South Georgia in an austral summer of 1999/2000. Oceanographic conditions in that year

33 around South Georgia were abnormal (i.e. anomalously high sea surface temperature to a relative

3419 year long-term mean). The diet of grey-headed albatrosses showed high seasonal variation,

35 shifting from cephalopods (42.9 \% by mass) in late February to Antarctic krill Euphausia

36 superba (58.3\%) in late April, and grey-headed albatrosses breeding performance was low

37 (16.8\%) . This study shows these albatrosses did not manage to find sufficient alternative prey

38 and highlight the risk to top predators if there is an increase in the frequency or severity of food

39 shortages in Antarctic waters.

40

41

42 


\section{INTRODUCTION}

Climate processes have a major impact on the structure and function of ecological systems (Stenseth et al. 2002). A wide range of studies have shown links between fluctuations in climate, and changes in terrestrial, freshwater and marine ecosystems worldwide (Wuethrich 2000; Attrill and Power 2002; Stenseth et al. 2002; Quetin and Ross 2003). In the marine environment, top predators, such as seabirds, have to cope with resources that are patchilydistributed and seasonally variable (Brooke 2004; Weimerskirch 2007; Fauchald 2009). For this reason, their ability to adapt to changing environmental constraints has an important influence on their breeding performance and population dynamics (Phillips et al. 1996; Lewis et al. 2006). Adaptation of seabirds and other marine organisms to environmental conditions may be immediate, or show a temporal lag of weeks, seasons, decades or even generations (Reid and 54 Croxall 2001a; Walther et al. 2002; Atkinson et al. 2004). For example, rhinoceros auklets Cerorhinca monocerata breeding in Japan respond within days to changes in the food web caused by fluctuations in ocean currents, resulting in a switch in diets from euphausiids to fish (Ito et al. 2009). Other studies have recorded major annual changes in the diets of seabirds in relation to environmental perturbation (Xavier et al. 2003a; Xavier et al. 2003b; Ito et al. 2009; Wang et al. 2009). Indeed, growth rates and survival of offspring of many seabirds and other marine predators are frequently related to the quantity or quality of prey consumed (Croxall et al. 1988; Phillips et al. 1996; Boyd et al. 2006).

The Southern Ocean is a highly dynamic marine ecosystem, currently showing signs of

64 2004; Meredith and King 2005). Seabirds are amongst the major consumers in the region

65 (Croxall and Prince 1980). Many species are also threatened by conflict with fisheries

66 (competition for the same stocks of prey, or incidental mortality), or predation by introduced

67 mammals (Croxall et al. 1998; Wood et al. 2000; Xavier et al. 2003b; Phillips et al. 2004b;

68 Croxall et al. 2012). They are known to feed on a range of prey, including fish, crustaceans, and

69 cephalopods in particular (Xavier et al. 2003a; Xavier et al. 2003b; Xavier and Croxall 2007).

70 However, no detailed study has ever assessed seasonal variation in their diet.

71 In 2000, oceanographic conditions were unusually warm close to South Georgia in March

72 and April, with sea surface temperature higher by up to $1^{\circ} \mathrm{C}$ compared with the average of the 
73 last 19 years in the region (for example, at $40.5^{\circ} \mathrm{W} 54.5^{\circ} \mathrm{S}$, the sea surface temperature was $743.92^{\circ} \mathrm{C}$ compared with $2.99^{\circ} \mathrm{C}$ for the average) (Xavier et al. 2003b). In April 2000, which is 75 the late chick-rearing period for grey-headed albatrosses, $89 \%$ of grey-headed albatrosses fitted 76 with satellite-transmitters $(\mathrm{n}=9)$ foraged far from the colony in Antarctic waters than recorded in 77 chick-rearing in other years (Wood et al. 2000; Xavier et al. 2003b; Catry et al. 2004; Phillips et 78 al. 2004a); grey-headed albatrosses usually forage north of South Georgia, in Antarctic Polar 79 Frontal Zone/sub-Antarctic waters during their chick-rearing period, feeding mostly on the 80 ommastrephid squid Martialia hyadesi, and on fish, with the consumption of M. hyadesi being 81 positively correlated to high breeding success (Rodhouse et al. 1996; Prince et al. 1999; Xavier 82 et al. 2003a; Xavier et al. 2003b) and also southwest to the Scotia Sea, South Shetlands and 83 Antarctic peninsula regions but the proportion using each areas show strong annual variation 84 (Wood et al. 2000; Xavier et al. 2003b; Phillips et al. 2004a). In 2000, trip duration was 85 unusually long, averaging 13.3 days (range 5-26 days), compared with a mean of 2-3 days 86 typical of the chick-rearing period in other years (Huin et al. 2000; Phillips and Croxall 2003), 87 which was reflected in a low breeding success (16, 8\%; Xavier et al. 2003a), the sixth worst of 88 the 24 years between 1989 and 2012 for which data are available (British Antarctic Survey, 89 unpublished data) for grey-headed albatrosses breeding at Bird Island. In this study, using a 90 unique dataset for the year 2000, we investigate how a top predator, the grey-headed albatross, 91 copes with seasonal changes in oceanographic conditions by analysing changes in diet

92 composition, and the implications for breeding performance. Therefore, aims of the study were 93 to (1) describe seasonal changes in the diet of grey-headed albatrosses at fine temporal scale 94 (samples collected every 2 weeks) between February and April 2000, and (2) relate changes in 95 diet to sea surface temperature anomalies in alternative foraging areas to examine relationships 96 with putative changes in distribution.

MATERIAL AND METHODS

99

100 Diet sampling

101

102

Food samples (stomach contents) were collected from grey-headed albatross chicks at Bird Island, South Georgia every 2 weeks from early February to late April, in 2000. Food 
103 sampling was by induced regurgitation after the chick had been fed by the parent, and has no 104 effect on chick survival or mass at fledging (Phillips 2006). These samples were analyzed on the

105 same day that they were obtained. The samples were weighed and the overall mass was recorded. 106 All components were sorted into categories (cephalopods, crustaceans, fish and others; the latter 107 comprising carrion, penguin feathers, barnacles and jellyfish), and fresh remains weighed 108 following Cherel et al. (2000) and Xavier et al. (2003a).

109 Within each component, fresh remains were identified according to Clarke (1986), 110 Boltovskoy (1999), Xavier et al. (2003b) and Xavier and Cherel (2009) and using reference 111 collections held at the British Antarctic Survey (BAS), UK and at the Institute of Marine 112 Research (IMAR), PT. Loose beaks were examined along with those extracted from the other 113 cephalopod remains when determining the species composition and size classes of cephalopods 114 consumed. The diet data was summarised as frequency of occurrence, proportions by number 115 and proportions by mass, following Xavier et al. (2003a).

\section{Oceanographic data}

118 Sea surface temperature anomalies (SSTa) were obtained from 4 reference locations 119 randomly selected across the study region in known foraging areas of grey-headed albatrosses 120 during chick-rearing (Xavier et al. 2003b; Phillips et al. 2004a); north of the Antarctic Polar 121 Front $\left(45.5^{\circ} \mathrm{S} 35.5^{\circ} \mathrm{W}\right)$, South Georgia region $\left(50.5^{\circ} \mathrm{S} 35.5^{\circ} \mathrm{W}\right)$, mid Scotia Sea $\left(55.5^{\circ} \mathrm{S} 40.5^{\circ}\right.$

$122 \mathrm{~W})$ and at the Antarctic Peninsula region (60.5 $\left.\mathrm{S} 50.5^{\circ} \mathrm{W}\right)$ (Figure 1). Annual variation was 123 assessed by comparing SSTa between 1982 and 2000. Weekly sea surface temperature anomalies 124 (SSTa, Reynolds et al., 2002) were obtained from

125 http://iridl.ldeo.columbia.edu/SOURCES/.NOAA/.NCEP/.EMC/.CMB/.GLOBAL/.Reyn_Smith 126 OIv2/.weekly/. Absolute dynamic height data, provided by Aviso (Archiving, Validation and 127 Interpretation of Satellite Oceanographic data) (Rio and Hernandez 2004), were overlaid with the 128 average position of the major oceanic fronts in the study region (Subantarctic front, Antarctic 129 Polar Front, Southern Antarctic Circumpolar Current front, Southern Boundary of the Antarctic 130 Circumpolar Current) in order to identify any substantial changes in the positions of these fronts. 131 Values for oceanographic parameters were obtained from the closest date to the diet sampling 132 (range: 0-2 days). 


\section{Statistical analysis}

All statistics were carried out using Minitab (Sowers Printing Company, Pennsylvania). We examined relationships between different diet parameters - the frequency of occurrence and

137 estimated mass of cephalopods, crustaceans and fish, and number of each of the main prey species, the ommastrephid squid Martialia hyadesi, cranchiid squid Galiteuthis glacialis,

139 onychoteuthid squid Kondakovia longimana, lamprey Geotria australis and Antarctic krill

140 Euphausia superba (hereafter referred as krill) - and SSTa obtained from the four reference

141 locations according to the sampling diet dates, by means of Spearman rank correlation

142 coefficient, $r_{s}$. Since multiple tests were performed, we applied the Bonferroni correction (1/

143 number of correlations carried out for each reference location) and interpreted correlation

144 patterns following Hills (1969). General Linear Models (GLMs) were used to test whether the 145 proportions of the various prey groups in the diet varied significantly across sampling periods.

146 Values are reported as mean \pm Standard Error (SE) unless stated otherwise.

\section{RESULTS}

\section{Seasonal variation in diet composition}

A total of 120 food samples were collected from grey-headed albatross chicks between early February and late April 2000 (i.e., 20 samples every 2 weeks). Average weight of food

152 samples changed significantly, from $271 \pm 24.6 \mathrm{~g}$ in early February to $202 \pm 20.7 \mathrm{~g}$ in late April 153 (ANOVA, $F_{5,114}=3.1, P=0.01$ ), decreasing throughout the sampling periods (Linear regression, $154 \quad \mathrm{~F}_{1,118}=4,86, P=0.03$, $\left.\mathrm{r} 2=4.0\right)$.

155 Regarding diet composition, when all samples were combined, grey-headed albatrosses 156 consumed mainly crustaceans (61 \% by mass), followed by fish (19 \%) and cephalopods (17\%)

157 (Figure 1; see also Xavier et al. 2003a). However, there were considerable changes between 158 sampling periods (Figure 2), including significant differences in the frequency of occurrence of 159 the components (crustaceans, fish and cephalopods; $\chi^{2}{ }_{10}=32.0, \mathrm{P}<0.01$ ). Results from the 160 GLMs also showed that the proportions by mass of crustaceans $\left(\mathrm{F}_{5,114}=4.53, \mathrm{P}<0.01\right)$ and 161 cephalopods $\left(\mathrm{F}_{5,114}=4.97, \mathrm{P}<0.01\right)$, but not fish $\left(\mathrm{F}_{5,114}=1.0, \mathrm{P}=0.40\right)$, differed significantly 162 between sampling periods. Cephalopods increased from $<1 \%$ by mass in early February to 42.9 
163

164

165

166

$\%$ (and were the most important prey group) in late February, whereas crustaceans were the most consumed prey group in all other periods (Figure 2). There were also considerable changes in species composition by number: the sub-Antarctic squid Martialia hyadesi was the most important cephalopod species in early February, but then declined in importance thereafter, as the proportion of the Antarctic squid species Galiteuthis glacialis increased (K. longimana was always the most important cephalopod consumed by mass; Figure 3). Within the fish component, G. australis was the most important by number in all sampling periods, but by mass Magnisudis prionosa was the most consumed fish prey in early February, and then declined in importance, as the proportion of G. australis increased (Figure 4). Krill dominated the crustacean component, by number (> in all sampling periods) and by mass (> $99 \%$ ) in all sampling periods (Figure 2).

\section{Oceanographic conditions within the foraging area of breeding grey-headed albatrosses}

Oceanographic conditions between the north of the Antarctic Polar Front (APF) and the Antarctic Peninsula were unusually warm during some months: SSTa north of the APF was warmer (i.e. positive SSTa), for most of the breeding cycle (late incubation to late chick-rearing) of grey-headed albatrosses (Dec. 1999, Jan. - Feb. 2000 and Apr. - May 2000; Figures 1 and 5), than the mean long-term average in the previous 19 years (1982-2000; Figure 5). Further south, around South Georgia, high SSTa values were observed slightly later, between January 2000 and April 2000 (Figure 5). In the mid Scotia Sea, abnormal SSTa was only apparent in April 2000 (Figure 5), and at the Antarctic Peninsula, SSTa was higher from March 2000 to July 2000 (Figure 5), which corresponds to the late chick-rearing period of grey-headed albatross.

Examination of absolute dynamic height data showed that this was due to widespread warming of surface waters rather than shifts in the position of the fronts of the Antarctic Circumpolar Current (ACC). Large-scale surface warming in this region has previously been recorded, most recently in 2009(Venables 2012).

\section{Relationships between prey availability and SSTa}

There were 2 significant correlations between values for the main diet parameters (i.e. frequency of occurrence and mass of crustaceans, cephalopod and fish; number of items of the most important prey: krill, Martialia hyadesi, Galiteuthis glacialis, Kondakovia longimana and 
193 lamprey) and SSTa at each reference location: the number of G. australis was

194 positivelycorrelated to SSTa in the South Georgia region (Spearman rank correlation; $r_{s}=0.943$;

$195 P=0.05$ ) and the mass of $M$. hyadesi was positively correlated with SSTa in the mid Scotia Sea

196 (Spearman rank correlation; $\left.r_{s}=-0.943 ; P=0.05\right)$ (). No other significant relationships or other

197 obvious patterns were evident.

\section{DISCUSSION}

Our study identified significant seasonal changes in the diet of grey-headed albatrosses at

202 biogeography, the reduction in Martialia hyadesi and lamprey, and increase in krill and

203 Galiteuthis glacialis in the diet represent shifts from feeding in the Antarctic Polar Frontal Zone

204 (APFZ) to waters at much higher latitudes. Despite this, breeding success in 2000 was poor

205 (16.8\%; Xavier et al. 2003a). In our study, the oceanographic conditions were unusually warm

206 close to South Georgia between January and April 2000, with sea surface temperature warmer by

207 up to $1^{\circ} \mathrm{C}$ in comparison with annual data between 1982 and 2000 (see results).

208 Grey-headed albatrosses tracked in April 2000 foraged predominantly in Antarctic 209 waters, mainly on the shelf or shelf-slope waters of the South Orkneys and South Shetlands, and

210 at the Antarctic Peninsula north of Adelaide Island feeding on krill (Xavier et al. 2003a). In

211 contrast, earlier in the season, the diet consisted predominantly by number of the subantarctic

212 squid Martialia hyadesi, which is obtained mainly at the APFZ (Rodhouse et al. 1996). The

213 switch to long trips carries an increased risk that the chick will die of starvation in the interim,

214 and hence breeding success in 2000 was ultimately poor. Previous studies at South Georgia

215 suggest that breeding failure in grey-headed albatrosses is associated with some years in which

216 krill (Croxall et al. 1999) or M. hyadesi (Xavier et al. 2003a) are scarce. This was the case in

217 1994, even though grey-headed albatrosses continued to forage north of South Georgia but fed

218 more on fish and less on squid than usual (Rodhouse et al. 1996; Prince et al. 1999). Together,

219 these results suggest that the key determinant of successful breeding in grey-headed albatrosses

220 is the availability of $M$. hyadesi, hence the significant positive correlation between the proportion

221 of this squid in the diet and breeding success (Xavier et al. 2003a) and SSTa (this study).

222 Feeding only on krill at the Antarctic Peninsula seems not to be a viable alternative, presumably 
223 because it is not sufficiently available/abundant in some years and often requires much longer

224 foraging trips to Antarctic Peninsula, which reduces overall provisioning rates.

226 cephalopod consumed by grey-headed albatrosses by mass in all sampling periods (Figure 2).

227 The biology and distribution of K. longimana is still poorly known, although it is known to occur

228 in Antarctic (circumpolar) and APFZ waters (Cherel and Weimerskirch 1999; Xavier et al.

229 1999), potentially mating/spawning on shelf areas (Cherel and Weimerskirch 1999) and be

230 available in the upper strata of the water column (Lu and Williams 1994) potentially accessible

231 live to grey-headed albatrosses throughout their foraging range breeding while breeding in South

232 Georgia (Croxall and Prince 1994; Phillips et al. 2004a; Xavier and Croxall 2007). Despite this

233 squid species occur regularly in the diets of grey-headed albatrosses (Xavier et al. 2003a; Xavier

234 and Cherel 2009), its availability is likely not to in high numbers as $K$. longimana is the main

235 cephalopod prey by mass in poor breeding success years (Xavier et al. 2003a; this study).

$236 \quad$ Galiteuthis glacialis was the most important cephalopod species in most sampling

237 periods by number (Figure 3). G. glacialis is a typical Antarctic species, being caught all around

238 the Southern Ocean (Xavier et al. 1999) and found in numerous Antarctic predators (Xavier and

239 Cherel 2009). Like K. longimana, G. glacialis is more abundant in the diet of grey-headed

240 albatrosses by number vin poor breeding success years (Xavier et al. 2003a; this study).

241 The lamprey G. australis, were the main prey in the fish component in grey-headed

242 albatrosses by number in all sampling periods (and by mass, except in early February, in which

243 M. prionosa was the most important; Figure 3) and was related to SSTa in the South Georgia

244 region. This agrees with previous studies, in which G. australis dominated the diet of grey-

245 headed albatrosses (Xavier et al. 2003a). Unlike K. longimana, G. australis had been the most

246 important fish species in both good and bad breeding years of grey-headed albatrosses (Xavier et

247 al. 2003a), suggesting that G. australis, known to occur in APFZ waters, is a prey regularly and

248 consistently available to this predator (Xavier et al. 2003a).

249 Our study showed correlations between SSTa and G. australis and M. hyadesi from the

250 diets of grey-headed albatrosses during chick-rearing, suggesting that changes in SSTa may

251 influence albatrosses foraging distribution. This high flexibility in feeding strategies is also

252 apparent in changes typical of the transition between different breeding stages. For example, 
253 grey-headed albatrosses breeding at Marion Island are known to forage north of this island 254 during incubation and southwest during chick-rearing (Nel et al. 2001). Similarly, black-browed 255 albatrosses breeding at Bird Island foraged predominantly around and to the northwest of Bird 256 Island during incubation, stayed on the shelf around South Georgia and Shag Rocks during 257 brood-guard, and tended to switch to more southerly Antarctic waters in chick-rearing (Phillips 258 et al. 2004a). Female grey-headed albatrosses from South Georgia forage in the APFZ, and 259 males in the APFZ and also far to the southwest and southeast in Antarctic waters during 260 incubation, and both sexes mainly in the APFZ in brood-guard (Phillips et al. 2004). During 261 chick-rearing, both sexes travel to the APFZ, and also southwest to the Scotia Sea, South 262 Shetlands and Antarctic peninsula regions but the proportion using each areas show strong 263 annual variation (Wood et al. 2000, Xavier et al. 2003a, Phillips et al. 2004, BAS unpublished 264 data). In addition, individual birds that travel first to the APFZ will, if they experience poor 265 feeding success, switch immediately to Antarctic waters without returning to the colony (Catry et 266 al. 2004). It would therefore appear that during chick-rearing, grey-headed albatrosses favour 267 waters around, or to the north of South Georgia in the APFZ when environmental conditions are 268 favourable (i.e., SSTa conditions are normal), but, as our seasonal trends in diet indicate, will 269 gradually change their foraging patterns if confronted by challenging environmental conditions, 270 as occurred in 2000.

271 We show that oceanographic conditions were atypically warm across the Scotia Sea 272 (including South Georgia) from September 1999 to May 2000 (Figure 1; Figure 5). Warming 273 anomalies were first observed north of the APF at the end of the austral winter in September 274 1999. Then, warming conditions extended further south, first around the intermediate reference 275 locations and eventually at the Antarctic Peninsula in late May. Typically, in years in terms of 276 both normal oceanographic conditions and good breeding performance (Xavier et al. 2003a), 277 grey-headed albatrosses forage at the APF, usually returning with the sub-Antarctic squid $M$. 278 hyadesi (Xavier et al. 2003a; Catry et al. 2004). Although M. hyadesi was still present in the diet 279 in March and April 2000, numbers were low (see results). Indeed, another predator of $M$. 280 hyadesi, the Patagonian toothfish Dissostichus eleginoides that, unlike grey-headed albatrosses 281 forages deep in the water column, also barely fed on M. hyadesi in 2000, indicating that 282 abundance of the latter was uncharacteristically low (Pilling et al. 2001; Xavier et al. 2002). This 
283 ties in with the shift between late Feb. and March to other squid, Galiteuthis glacialis and 284 Kondakovia longimana, which are typically Antarctic species (Xavier et al. 1999), and to krill. 285 Lamprey, which is a typically subantarctic species, was regularly present in the diet of grey286 headed albatrosses throughout the whole breeding season (see results), probably consumed 287 during the small proportion of trips to the APFZ (Xavier et al. 2003a). Lamprey distribution may 288 also extend further south in warm years, but this, and indeed many other aspects of the life cycle 289 of oceanic lamprey, including their host and how they become available to albatrosses at South 290 Georgia, are unknown (Potter et al. 1979).

291 Changes in the diet of grey-headed albatrosses in this study were highly correlated with 292 environmental conditions. The proportions of crustaceans and fish by mass, as well as the 293 number of several squid species, were significantly related to SSTa. Temperature anomalies in 294 the South Pacific sector of the Southern Ocean are propagated via the ACC into the South 295 Atlantic on time scales of more than 1 year, whereas atmospheric processes related to ENSO and 296 the Southern Annular Mode have a direct influence on shorter time scales ( $<6$ months) (Murphy 297 et al. 2007a). These changes in SSTa across the South Atlantic sector are related to the 298 recruitment and dispersal of krill (Murphy et al. 2007a). The density and distribution of krill has 299 exhibited dramatic spatial and temporal fluctuations in the southwest Atlantic, where $>50 \%$ of 300 krill in the Southern Ocean are concentrated, and has declined since the 1970s (Atkinson et al. 301 2004). This oceanographically driven variation in krill population dynamics and abundance has 302 affected dependent predators, including some seabirds and marine mammal predators (Croxall et 303 al. 1999; Reid and Croxall 2001b). In our study, we demonstrate that there was a shift in the diet 304 of grey-headed albatrosses, which may be related to a functional link between the oceanographic 305 conditions and abundance/availability of krill, fish and squid, that affected the breeding 306 performance of albatrosses, reducing their chick survival. Such propagating anomalies, mediated 307 through physical and trophic interactions, are likely to be an increasingly important component 308 of variation in ocean ecosystems in the light of predicted anthropogenic climatic change.

309 The close examination of the diet of grey-headed albatrosses provided a good insight into 310 seasonal variation (Table 1). Although there was little change in the species composition of the 311 crustacean components, and krill tended to dominate, the fish and cephalopod components of the 312 diet changed significantly (Table 1). Furthermore, within these components, the importance of 
313 particular species, changed considerably, with G. glacialis (by number) and G. australis (by 314 mass) increasing over time over time (Figures 3 and 4). These changes would not have been 315 identified if only looking at the overall diet (i.e., if all samples had been pooled). Overall, this 316 study clearly demonstrates how top predators may respond in years when environmental 317 conditions are unfavourable. Despite this flexibility, breeding success was poor, which from a 318 conservation perspective is of particular concern for the study species, the grey-headed albatross, 319 given that the South Georgia population is the largest in the world, and breeds in a hotspot of 320 environmental variability (Murphy et al. 2007b; Murphy et al. 2007c).

322 Acknowledgements. We thank Bird Island staff especially Simon Berrow, Richard Humpidge, 323 Nik Aspey and Mark Jessop for help in collecting the samples, Simon Berrow and Robert Taylor

324 for useful discussions on the field protocol, Rachael Shreeve for valuable advice on crustacean 325 identification and Filipe Ceia, Jaime Ramos and Vitor Paiva for statistical discussions. We are 326 particularly grateful to Paul Rodhouse and Phil Trathan for their advice through the project. This 327 research was initially evaluated by an ethical committee and it was supported by the Ministry of 328 Science and Technology, Portugal (Fundação para a Ciência e a Tecnologia; FCT) and by the 329 British Antarctic Survey, UK. J.X. was funded by FCT and M.L. was funded by a Marie Curie 330 Individual Fellowship (PIEF-GA-2008-220063) and Juan de la Cierva postdoctoral programme 331 (JCI-2010-07639, Ministerio de Ciencia e Innovación). The altimeter products were produced 332 by Ssalto/Duacs and distributed by Aviso, with support from Cnes

333 (http://www.aviso.oceanobs.com/duacs/).

\section{REFERENCES}

Atkinson A, Siegel V, Pakhomov EA, Rothery P (2004) Long-term decline in krill stock and increase in salps within the Southern Ocean. Nature 432: 100-103

Attrill MJ, Power M (2002) Climatic influence on a marine fish assemblage. Nature 417: 275278

Boyd IL, Wanless S, Camphusysen CJ (2006) Top predators in marine ecosystems: their role in monitoring and management. Cambridge University Press

Brooke ML (2004) Albatrosses and petrels across the world. Oxford University Press

Catry P, Phillips RA, Phalan B, Silk JRD, Croxall JP (2004) Foraging strategies of grey-headed albatrosses Thalassarche chrysostoma: integration of movements, activity and feeding events. Mar Ecol Prog Ser 280: 261-273 
Cherel Y, Weimerskirch H (1999) Spawning cycle of onychoteuthid squids in the southern Indian Ocean: new information from seabird predators. Mar Ecol Prog Ser 188: 93-104

Cherel Y, Weimerskirch H, Trouve C (2000) Food and feeding ecology of the neritic-slope forager black- browed albatross and its relationships with commercial fisheries in Kerguelen waters. Mar Ecol Prog Ser 207: 183-199

Clarke MR (1986) A handbook for the identification of cephalopod beaks. Clarendon Press, Oxford

Croxall JP, Butchart SHM, Lascelles B, Stattersfield AJ, Sullivan B, Symes A, Taylor P (2012) Seabird conservation status, threats and priority actions: a global assessment. Birdlife Conserv Int 22: 1-34

Croxall JP, McCann TS, Prince PA, Rothery P (1988) Reproductive performance of seabirds and seals at South Georgia and Signy Island, South Orkney Islands, 1976-1987: implications for Southern Ocean monitoring studies. In: Sahrhage D (ed) Antarctic Ocean and Resources Variability. Springer-Verlag, Berlin, pp 261-285

Croxall JP, Prince PA (1980) Food, feeding ecology and ecological segregation of seabirds at South Georgia. Biol J Linn Soc 14: 103-131

Croxall JP, Prince PA (1994) Dead or alive, night or day: how do albatrosses catch squid? Antarct Sci 6: 155-162

Croxall JP, Prince PA, Rothery P, Wood AG (1998) Population changes in albatrosses at South Georgia. In: Robertson G, Gales R (eds) Albatross Biology and Conservation. Surrey Beatty \& Sons, Chipping Norton, Australia, pp 69-83

Croxall JP, Reid K, Prince PA (1999) Diet, provisioning and productivity responses of marine predators to differences in availability of Antarctic krill. Mar Ecol Prog Ser 177: 115-131

Fauchald P (2009) Spatial interaction between seabirds and prey: review and synthesis. Mar Ecol Prog Ser 391: 139-151

Hills M (1969) On looking at large correlation matrices. Biometrika 56: 249-253

Huin N, Prince PA, Briggs DR (2000) Chick provisioning rates and growth in black-browed albatross Diomedea melanophris and grey-headed albatross D. chrysostoma at Bird Island, South Georgia. Ibis 142: 550-565

Ito M, Minami H, Tanaka Y, Watanuki Y (2009) Seasonal and inter-annual oceanographic changes induce diet switching in a piscivorous seabird. Mar Ecol Prog Ser 393: 273-284

King JC (1994) Recent climate variability in the vicinity of the Antarctic Peninsula. Int J Climatol 14: 357-369

Lewis S, Grémillet D, Daunt F, Ryan P, Crawford RJM, Wanless S (2006) Using behavioural variables to identify proximate causes of population change in a seabird. Oecologia 147: 606-614

Lu CC, Williams R (1994) Kondakovia longimana Filippova, 1972 (Cephalopoda: Onychoteuthidae) from the Indian Ocean sector of the Southern Ocean. Antarct Sci 6: 231-234

Meredith MP, King JC (2005) Rapid climate change in the ocean west of the Antarctic Peninsula during the second half of the $20^{\text {th }}$ century. Geophys Res Lett 32: L19604

Murphy EJ, Trathan PN, Watkins JL, Reid K, Meredith MP, Forcada J, Thorpe SE, Johnston NM, Rothery P (2007a) Climatically driven fluctuations in Southern Ocean ecosystems. Proc. R. Soc. B 274: 3057-3067 
Murphy EJ, Trathan PN, Watkins JL, Reid K, Meredith MP, Forcada J, Thorpe SE, Johnston NM, Rothery P (2007b) Climatically driven fluctuations in Southern Ocean ecosystems. Proc R Soc B 274: 3057-3067

Murphy EJ, Watkins JL, Trathan PN, Reid K, Meredith MP, Thorpe SE, Johnston NM, Clarke A, Tarling GA, Collins MA, Forcada J, Shreeve RS, Atkinson A, Korb R, Whitehouse MJ, Ward P, Rodhouse PG, Enderlein P, Hirst AG, Martin AR, Hill SL, Staniland IJ, Pond DW, Briggs DR, Cunningham NJ, Fleming AH (2007c) Spatial and temporal operation of the Scotia Sea ecosystem: a review of large-scale links in a krill centred food web. Phil Trans R Soc B 362: 113-148

Nel DC, Lutjeharms JRE, Pakhomov EA, Ansorge IJ, Ryan PG, Klages NTW (2001) Exploitation of mesoscale oceanographic features by grey-headed albatross Thalassarche chrysostoma in the southern Indian Ocean. Mar Ecol Prog Ser 217: 15-26

Phillips RA (2006) Efficacy and effects of diet sampling of albatross chicks. Emu 106: 305-308

Phillips RA, Caldow RWG, Furness RW (1996) The influence of food availability on the breeding effort and reproductive success of Arctic skuas Stercorarius parasiticus. Ibis 138: 410-419

Phillips RA, Croxall JP (2003) Control of provisioning in grey-headed albatrosses: do adults respond to chick condition? . Can J Zool 81: 111-116

Phillips RA, Silk JRD, Phalan B, Catry P, Croxall JP (2004a) Seasonal sexual segregation in two Thalassarche albatross species: competitive exclusion, reproductive role specialization or foraging niche divergence? Proc R Soc Lond B 271: 1283-1291

Phillips RA, Silk JRD, Phalan B, Catry P, Croxall JP (2004b) Seasonal sexual segregation in two Thalassarche albatross species: competitive exclusion, reproductive role specialization or foraging niche divergence? Proc. R. Soc. Lond. B 271: 1283-1291

Pilling GM, Purves MG, Daw TM, Agnew DA, Xavier JC (2001) The stomach contents of Patagonian toothfish around South Georgia (South Atlantic). J Fish Biol 59: 1370-1384

Potter IC, Prince PA, Croxall JP (1979) Data on the adult marine and migratory phases in the life cycle of the southern hemisphere lamprey, Geotria australis Gray. Env Biol Fish 4: 6569

Prince PA, Weimerskirch H, Wood AG, Croxall JP (1999) Areas and scales of interactions between albatrosses and the marine environment: species, populations and sexes. In: Adams NJ, Slotow RH (eds) Proceedings of 22nd Ornithological Congress, Durban, August 1998. BirdLife South Africa, Johannesburg, pp 2001-2020

Quetin LB, Ross RM (2003) Episodic recruitment in Antarctic krill Euphausia superba in the Palmer LTER study region. Mar Ecol Prog Ser 259: 185-200

Reid K, Croxall JP (2001a) Environmental response of upper trophic-level predators reveals a system change in an Antarctic marine ecosystem. Proc Roy Soc Lond B 268: 377-384

Reid K, Croxall JP (2001b) Environmental response of upper trophic-level predators reveals a system change in an Antarctic marine ecosystem. Proceedings of the Royal Society of London Series B-Biological Sciences 268: 377-384

Rio M-H, Hernandez F (2004) A mean dynamic topography computed over the world ocean from altimetry, in situ measurements, and a geoid model. J Geophys Res 109: 12032

Rodhouse PG, Prince PA, Trathan PN, Hatfield EMC, Watkins JL, Bone DG, Murphy EJ, White MG (1996) Cephalopods and mesoscale oceanography at the Antarctic Polar Front: 

satellite tracked predators locate pelagic trophic interactions. Mar Ecol Prog Ser 136: 37-

Stenseth NC, Ottersen G, Hurrell JW, Chan KS, Lima M (2002) Ecological effects of climate fluctuations. Science 297: 1292-1296

Venables (2012) Fronts and habitat zones in the Scotia sea. Deep-Sea Res II 59-60: 14-24

Walther GR, Post E, Convey P, Menzel A, Pearmesan C, Beebee TJC, Fromentin JM, Guldberg OH, Bairlein F (2002) Ecological responses to recent climate change. Nature 416: 389395

Wang SW, Iverson SJ, Springer AM, Hatch SA (2009) Spatial and temporal diet segregation in northern fulmars Fulmarus glacialis breeding in Alaska: insights from fatty acid signatures. Mar Ecol Prog Ser 377: 299-307

Weimerskirch H (2007) Are seabirds foraging for unpredictable resources? Deep-Sea Res II 54: 211-223

Wood AG, Naef-Daenzer B, Prince PA, Croxall JP (2000) Quantifying habitat use in satellitetracked pelagic seabirds: application of kernel estimation to albatross locations. J Avian Biol 31: 278-286

Wuethrich B (2000) How climate change alters rhthms of the wild. Science 287: 793-795

Xavier JC, Cherel Y (2009) Cephalopod beak guide for the Southern Ocean. British Antarctic Survey

Xavier JC, Croxall JP (2007) Predator-prey interactions: why do larger albatrosses feed on bigger squid? J Zool Lond 271: 408-417

Xavier JC, Croxall JP, Reid K (2003a) Inter-annual variation in the diet of two albatross species breeding at South Georgia: implications for breeding performance. Ibis 145: 593-610

Xavier JC, Croxall JP, Trathan PN, Wood AG (2003b) Feeding strategies and diets of breeding grey-headed and wandering albatrosses at South Georgia. Mar Biol 143: 221-232

Xavier JC, Rodhouse PG, Purves MG, Daw TM, Arata J, Pilling GM (2002) Distribution of cephalopods recorded in the diet of Patagonian toothfish (Dissostichus eleginoides) around South Georgia. Polar Biol 25: 323-330

Xavier JC, Rodhouse PG, Trathan PN, Wood AG (1999) A Geographical Information System (GIS) atlas of cephalopod distribution in the Southern Ocean. Antarctic Science 11: 6162 

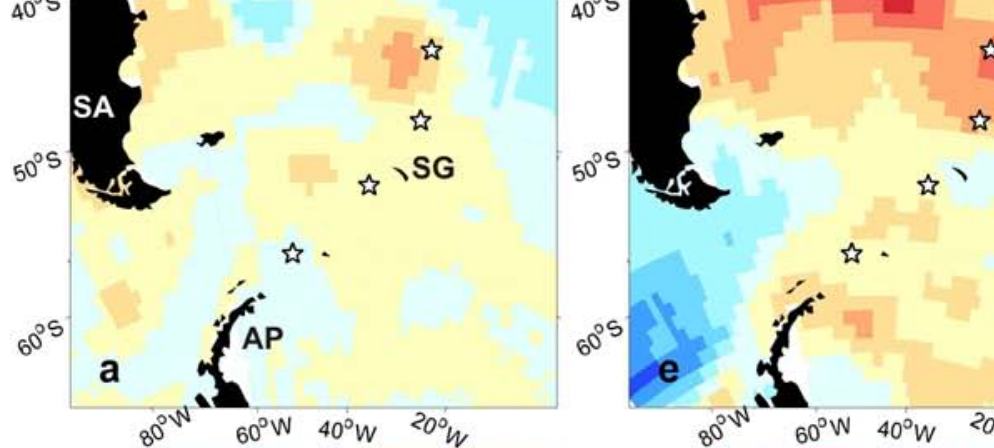

$60^{\circ} \mathrm{W} 40^{\circ} \mathrm{W} \quad{ }^{20} \mathrm{~W}$
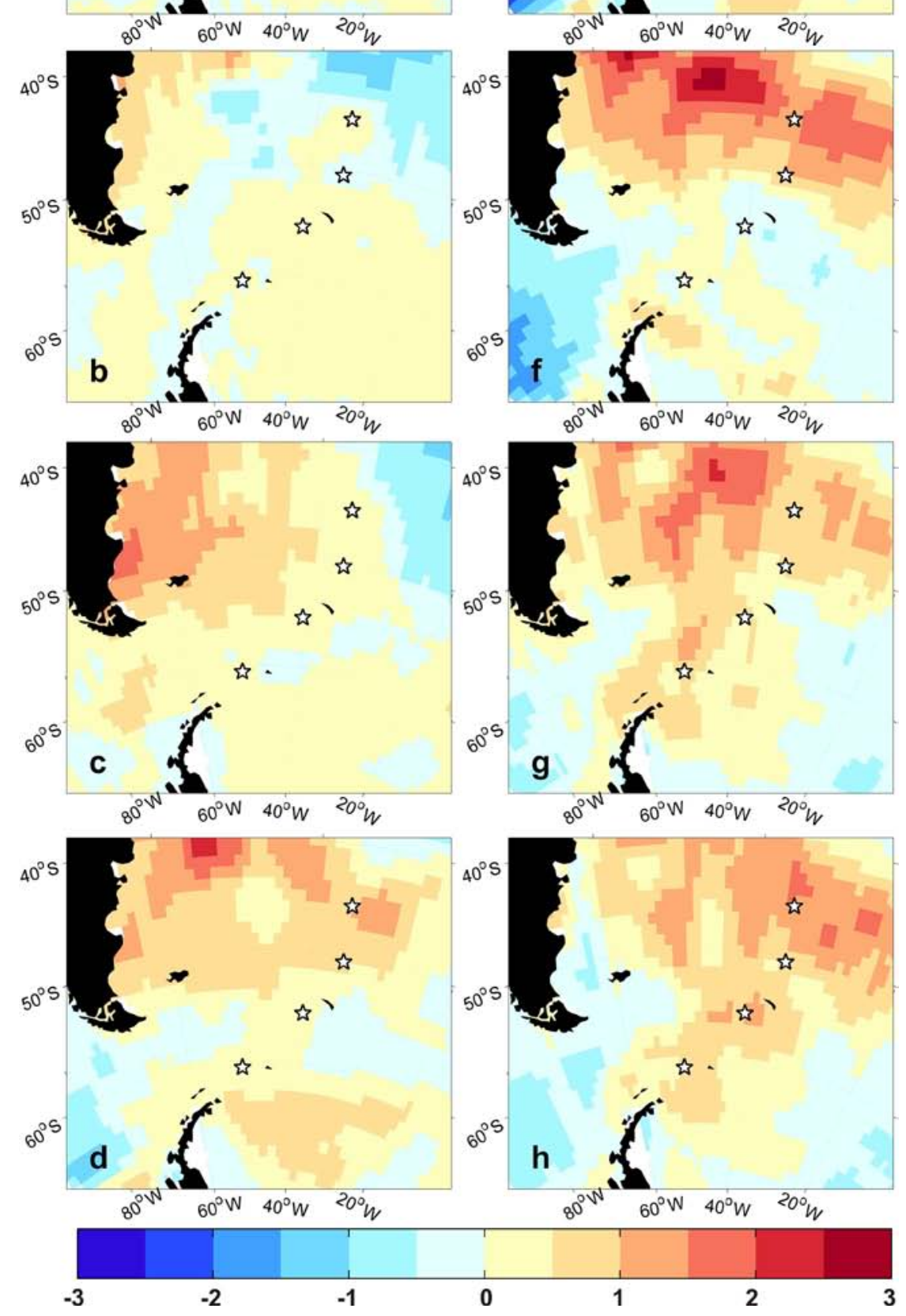

Figure 1. Map of the study region (SA- South America; SG- South Georgia; AP - Antarctic Peninsula), locations of the 4 reference locations (Star symbols) and oceanographic conditions (monthly mean sea surface temperature anomaly $\left({ }^{\circ} \mathrm{C}\right.$ ) relative to $1971-2000$ mean) between September 1999 (A) to April $2000(\mathrm{H})$. Contour lines are plotted and labelled every $0.5^{\circ} \mathrm{C}$, anomalies $<0^{\circ} \mathrm{C}$ have dashed lines, anomalies $\geq 0{ }^{\circ} \mathrm{C}$ have solid lines. 


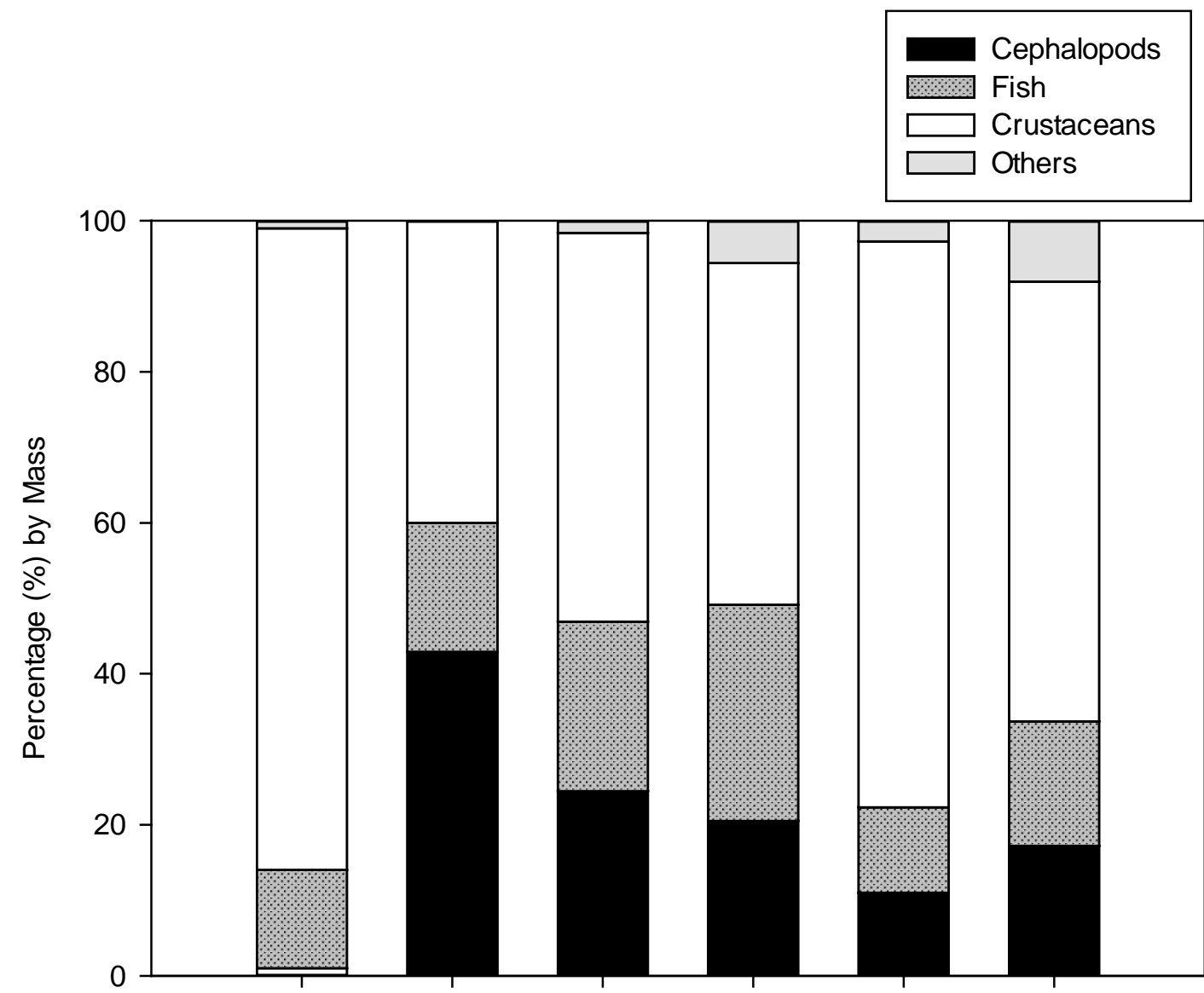

Early Feb. Late Feb. Early Mar. Late Mar. Early Apr. Late Apr.

523 Figure 2. General composition of the diet of grey-headed albatrosses at Bird Island (south

524 Georgia), between February and April 2000.

525

526 


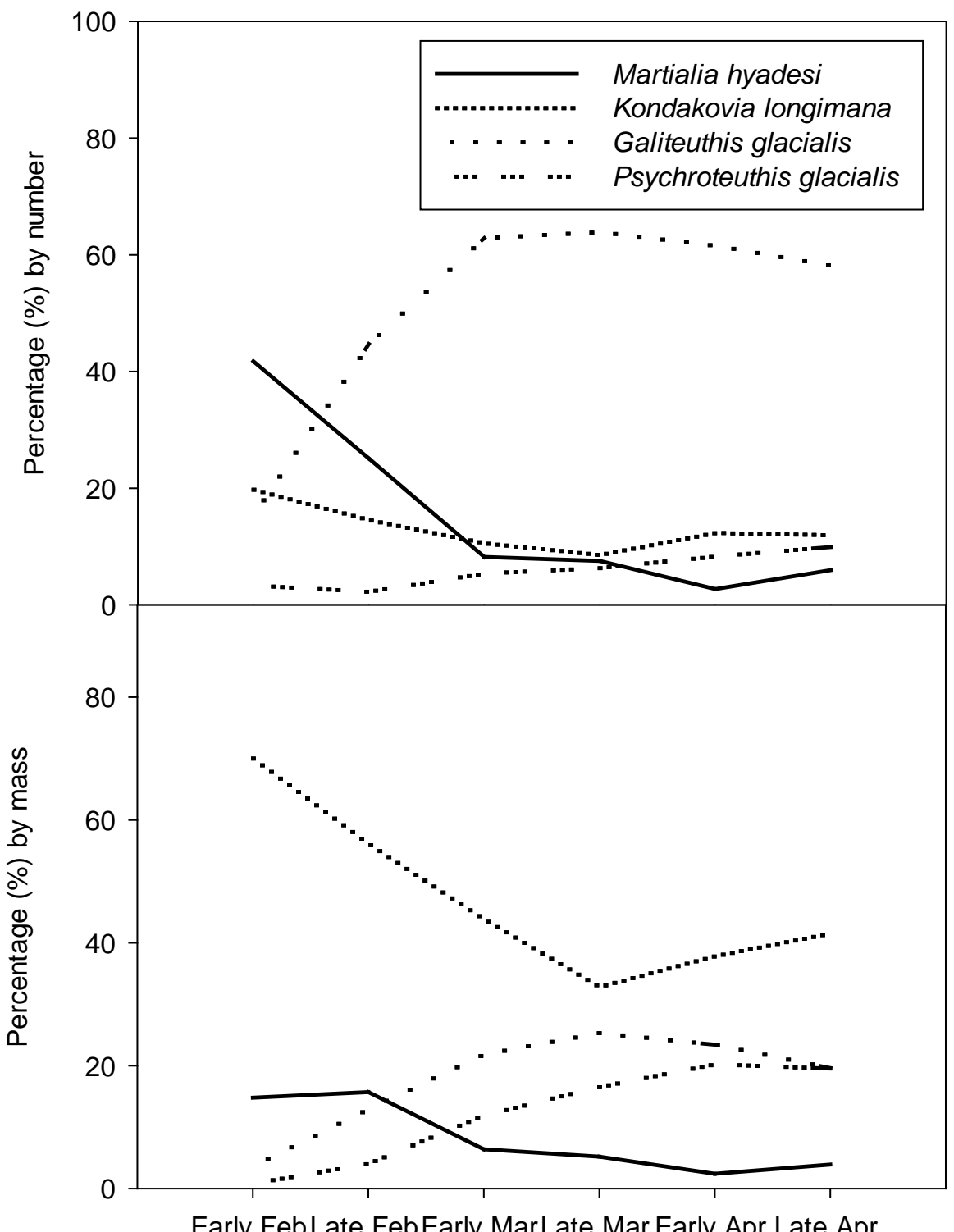

Figure 3. Seasonal changes of the most important cephalopod species, by number and by mass, 534 in the diet of grey-headed albatrosses between February and April 2000. 


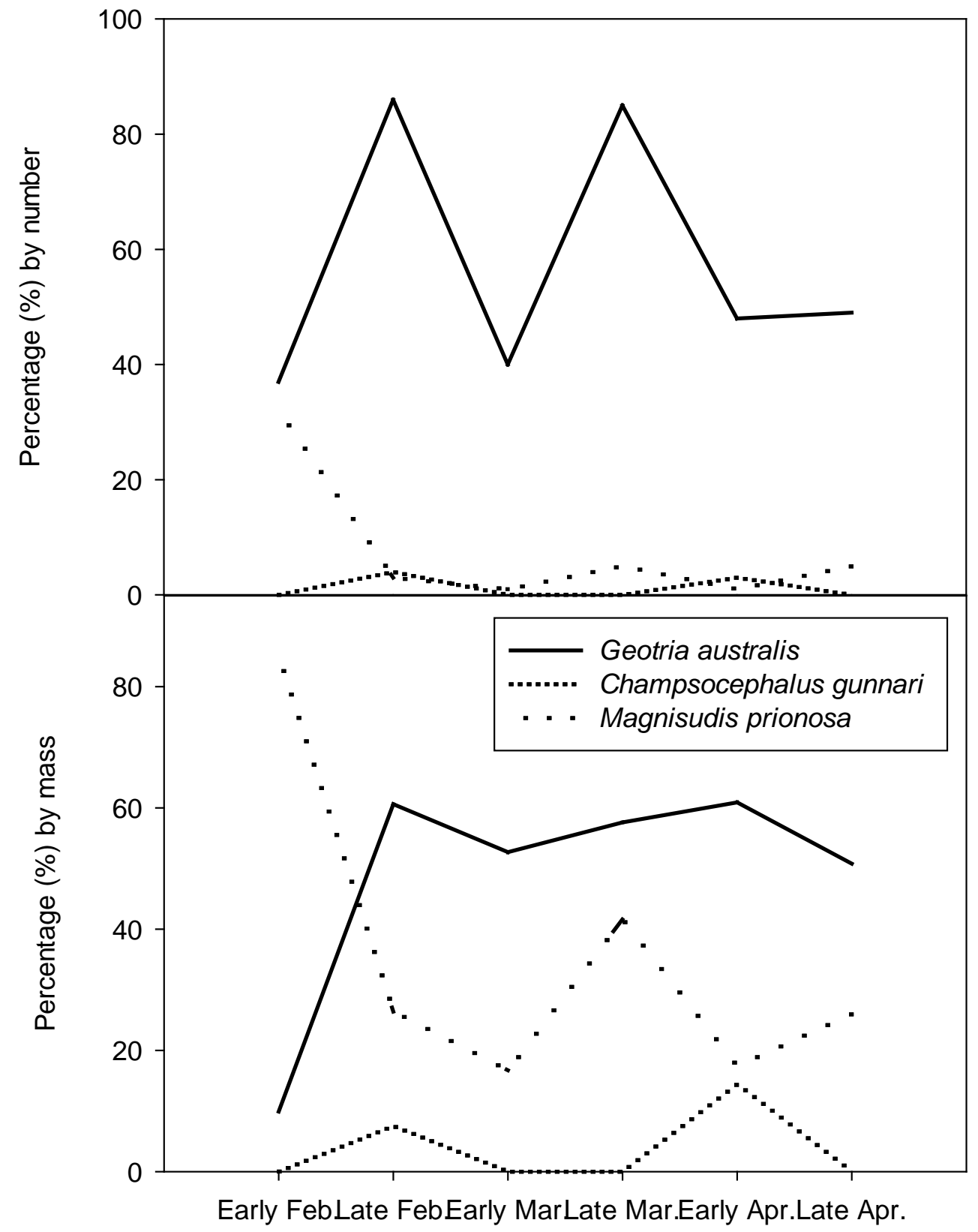

Sampling period

Figure 4. Seasonal changes of the most important fish species, by number and by mass, in the 541 diet of grey-headed albatrosses between February and April 2000. 


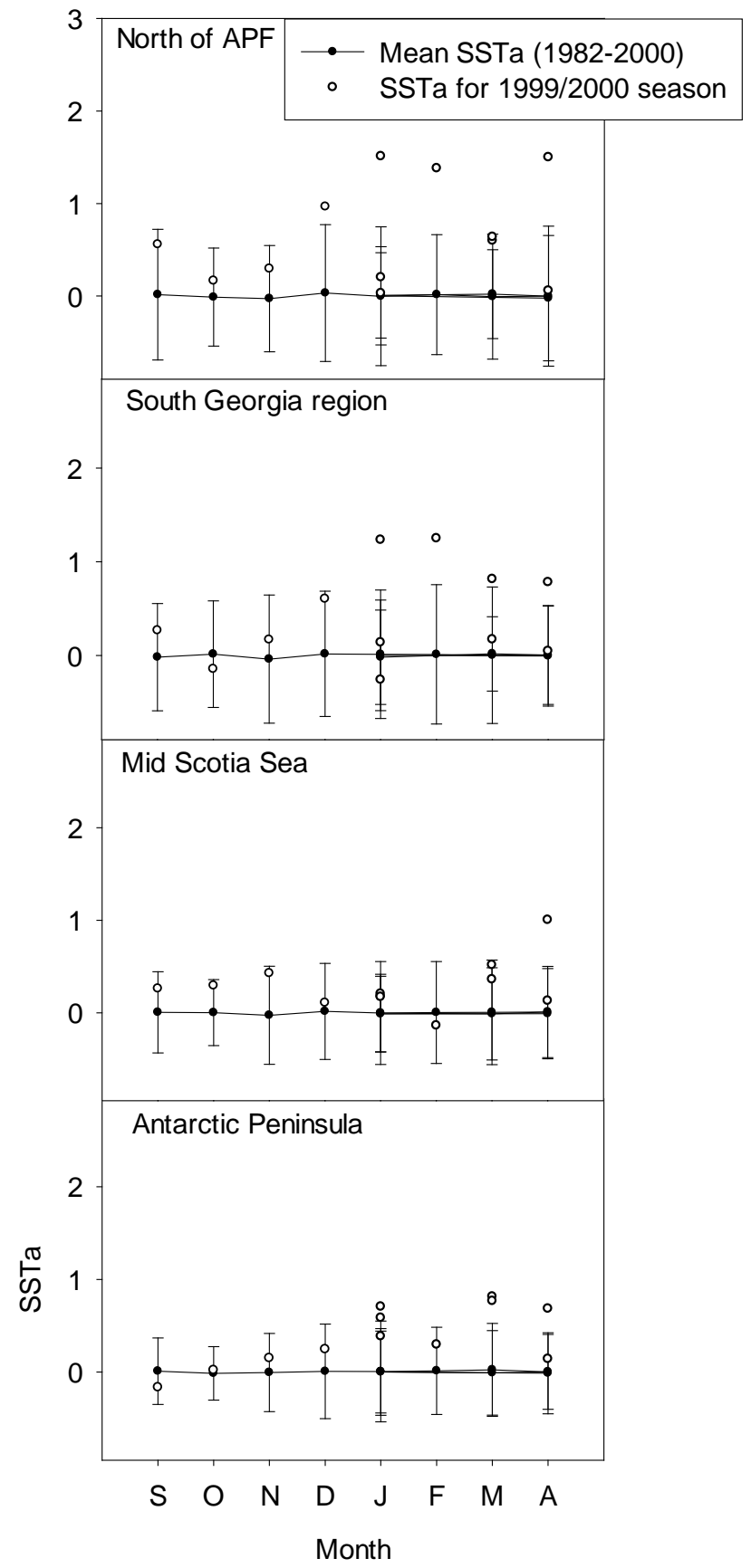

543

544 Figure 5. Mean monthly sea surface temperatures anomalies (SSTa) between 1982- 2000 at 4

545 randomly-selected reference locations (black symbols) in the study area: north of the Antarctic

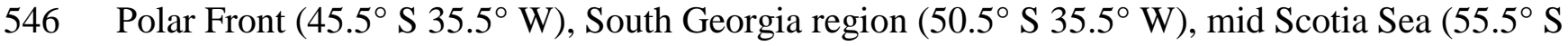

$\left.54740.5^{\circ} \mathrm{W}\right)$ and Antarctic Peninsula $\left(60.5^{\circ} \mathrm{S} 50.5^{\circ} \mathrm{W}\right)$. White symbols are values for the

548 1999/2000 season. The values are given mean \pm SD. 
Table 1. Seasonal variation in the diet of grey-headed albatrosses from Bird Island, South Georgia in 2000. (n= number of samples; F (\%) = Frequency of occurrence; $\mathrm{N}(\%)$ = percentage of number of individuals (in parentheses there are the raw values); $\mathrm{M}(\%)$ = percentage of the proportion by mass). Only prey that represented $\geq 5 \%$ by mass in the diet were included.

\begin{tabular}{|c|c|c|c|c|c|c|c|c|c|}
\hline \multirow[b]{3}{*}{ Species } & \multirow{2}{*}{$\begin{array}{l}\text { Early February } \\
\qquad(\mathrm{n}=20)\end{array}$} & \multirow{2}{*}{$\begin{array}{l}\text { Late February } \\
\qquad(n=20)\end{array}$} & \multirow{2}{*}{$\begin{array}{l}\text { Early March } \\
\qquad(n=20)\end{array}$} & \multirow{2}{*}{$\begin{array}{l}\text { Late March } \\
\qquad(\mathrm{n}=20)\end{array}$} & \multirow{2}{*}{$\begin{array}{l}\text { Early April } \\
\qquad(n=20)\end{array}$} & \multirow{2}{*}{$\begin{array}{l}\text { Late April } \\
\qquad(\mathrm{n}=20)\end{array}$} & \multicolumn{2}{|c|}{ Overall } & \multirow[b]{3}{*}{ M (\%) } \\
\hline & & & & & & & & & \\
\hline & $F(\%)$ & $F(\%)$ & $F(\%)$ & $F(\%)$ & $F(\%)$ & $F(\%)$ & $F(\%)$ & N (\%) & \\
\hline CEPHALOPODS & & & & & & & & & $17 \pm 3$ \\
\hline Alluroteuthis antarcticus & 5 & 30 & 20 & 50 & 40 & 40 & 31 & (58) 3 & 5.2 \\
\hline Galiteuthis glacialis & 35 & 100 & 95 & 85 & 85 & 60 & 77 & (1218) 57 & 19.4 \\
\hline Kondakovia longimana & 40 & 90 & 85 & 65 & 80 & 55 & 69 & (256)12 & 44.5 \\
\hline Martialia hyadesi & 25 & 80 & 45 & 60 & 30 & 20 & 43 & (251) 12 & 7.7 \\
\hline Psychroteuthis glacialis & 15 & 25 & 45 & 40 & 45 & 45 & 36 & (129) 6 & 12.9 \\
\hline Gonatus antarcticus & 15 & 70 & 50 & 45 & 20 & 25 & 38 & (82) 4 & 3.3 \\
\hline Moroteuthis knipovitchi & 5 & 35 & 25 & 20 & 15 & 15 & 19 & (129) 2 & 4.0 \\
\hline FISH & & & & & & & & & $19 \pm 3$ \\
\hline Geotria australis & 15 & 75 & 70 & 65 & 60 & 35 & 47 & (403) 62 & 49.3 \\
\hline Champsocephalus gunnari & 0 & 5 & 0 & 0 & 10 & 0 & 3 & (10) 2 & 3.7 \\
\hline Magnisudis prionosa & 20 & 15 & 5 & 15 & 5 & 5 & 11 & (27) 4 & 36.7 \\
\hline CRUSTACEANS & & & & & & & & & $61 \pm 4$ \\
\hline Euphausia superba & 100 & 70 & 100 & 85 & 95 & 80 & 89 & $>99$ & 99.6 \\
\hline OTHERS & & & & & & & & & $3 \pm 1$ \\
\hline
\end{tabular}

